\title{
Policy Insights: How Do Employment Policies Work to Benefit College Graduates in Zhejiang Province
}

\author{
Rendong Jin ${ }^{1, *}$

\begin{abstract}
${ }^{1}$ Zhejiang Tongji Vocational College of Science and Technology, Hangzhou, Zhejiang 311231, China
*Corresponding author. Email: z20520030803@zjtongji.edu.cn
\end{abstract}

\begin{abstract}
How do employment policies work to benefit college graduates has been an important concern for people's livelihood. The purpose of the present work is to figure out how Zhejiang's employment policies benefit graduates, most of whom are employed in small and micro-enterprises. Jinhua city is taken as an example to carry out the survey and research to find out how college graduates work in small and micro-enterprises and how the government's policies operate there. It is concluded from the research that the pioneer policies in Zhejiang Province have been carried out quickly and systematically, and the overall effect is good. But some problems still exist including the lack of new policies for college graduates working in small and microenterprises and the operability of the implementation of the employment policies for college graduates. It is suggested that new policies should be released and the policies working effectively also need to be kept, and the beneficiaries should be classified and the operability of policy implementation should be improved.
\end{abstract}

Keywords: Employment Policy, College Graduates, Policy Evaluation, Zhejiang Province

\section{INTRODUCTION}

Employment is the foundation of people's livelihood, and to improve ordinary college graduates' job hunting efficiency can promote social harmony and stability and economy's transformation and upgrading. Small and micro-enterprises contribute more than $60 \%$ of GDP, more than $50 \%$ of tax revenue, more than $80 \%$ of urban labour employment and more than $70 \%$ of technological innovation. They employ most of the college graduates [1]. In 2018 alone, a total of 15.12 million people were employed by small and micro-enterprises [2]. At the end of 2019 , the number of registered small and micro-enterprises reached 2.224 million, accounting for $87.7 \%$ of the whole nation's enterprises, and thus have provided a large number of college graduates with jobs. This research focuses on how Zhejiang's employment policies benefit universities graduates, as there are smaller and micro-enterprises than other provinces. The policies for resuming work and production and stabilizing employment issued by Zhejiang Province since the COVID-19 epidemic have been sorted out and analyzed with the data collected online.

\section{POLICY INVESTIGATION}

The present research focuses on employment policies launched in March 2020 when the COVID-19 broke out.

\subsection{Situation of Policy Release}

Through the online survey, a total of 179 policies were collected, among which, 38 are national-level policies, 17 are provincial, 47 are of Hangzhou (including subordinate districts and counties), and 12 are of Ningbo.

First of all, Hangzhou has responded quickly as a model as the capital city, and its subordinate districts have implemented according to the provincial guidance, and thus leads the practice of other cities' resuming work and production. Secondly, the province's assistance policies have been effective, and Zhejiang's economic operations have continued to rebound. Although in the retail industry where small and micro-enterprises are concentrated, the province's total retail sales of consumer goods was 345.7 billion yuan from January to February, decreasing $18.0 \%$ compared with last year. Then the total retail sales amounted to 660.5 billion yuan, which turned from a decline to an increase of $1.7 \%$. The economy continued to rebound. Thirdly, the employment situation of college students is still not optimistic. In the first half of the year, the province's total retail sales of consumer goods was $1,193.9$ billion yuan, a decrease of $6.3 \%$ compared with last year, and the rate of decline narrowed by 8.4 percentage points from the first quarter. Under such a situation, the scale of employment of enterprises has decreased compared with the same period of last year, and the employment of college graduates has been affected. According to the statistics from the Zhejiang Provincial Bureau of Statistics in the first quarter of 2020, the urban unemployment rate was $4.7 \%$, which is an increase of $0.4 \%$ 
from the previous months, reaching a new height in recent years. [3]

\subsection{Policy Content}

\subsubsection{Employment Policy}

The policy jointly issued by the Ministry of Human Resources and Social Security, the Ministry of Education, the Ministry of Finance, the Ministry of Transport, and the National Health Commission is the country's main guiding document on employment.

In terms of employment policy, there are 5 policies closely focus on "employment" (new employment), and 98 policies related to "employment"; 6 policies closely focus on "enterprise employment" (all employment), and 53 policies are related to "enterprise employment"; 9 policies closely focus on "talent" (talent employment), and 77 policies are related to "talent".

It can be seen that stabilizing employment, guaranteeing employment, and attracting talents are the main focus and support directions of the series of policies to help resume work and production. Each region dynamically adapts to regional industrial resumption needs to issue policies flexibly, but there are still problems. Taking new job policy as an example. New graduates are treated differently in some areas based on whether they graduate from a "985" or a "211" level elite university, or based on their degree (doctoral, master, undergraduate and higher vocational).

These policies benefit to different areas. For enterprises, 55 policies are released to ensure the employment of key enterprises; 77 policies are related to small, medium and micro-enterprises. For employees, there are 22 policies related to migrant labour, 14 policies related high-level talents inside and outside the province, 7 policies related to fresh graduates, but only 2 policies are related to graduates from higher vocational colleges.

Different educational background groups have different employment difficulties. Many new graduates couldn't find jobs the last June, the proportion of undergraduates not employed was the highest at $65.6 \%$, followed by vocational students at $26.2 \%$, and the proportions of masters and doctors were $8.0 \%$ and $0.14 \%$, respectively. [4]

There are different employment benefits for graduates with different educational background. For example, some counties and cities treat different graduates differently, announcing that during the implementation of the policy, only graduates from " 985 " or " 211 " level elite universities could receive an employment subsidy of 420 yuan per month for their first job. Graduates from vocational colleges could not enjoy such a benefit.

\subsubsection{Other Policy}

In terms of non-employment policies, there are 74 policies related to encouraging companies to carry out online skills training; 11 policies related to employment grants; 22 policies related to optimizing online recruitment; 49 policies related to increasing unemployment insurance; and 48 policies related to encouraging entrepreneurship.

According to the survey, the main employment assistance policies were issued by General Office of the Development and Reform Commission, the General Office of the Ministry of Human Resources and Social Security, the General Office of the Ministry of Industry and Information, and the General Office of the All-China Federation of Trade Unions jointly to formulate online training, and $81.9 \%$ of these employment assistance policies are on this focus. The second concern is about unemployment insurance and to encourage entrepreneurship, and about $50 \%$ of these employment assistance policies are on this focus. Therefore, other employment supporting policies in Zhejiang province are issued systematically and comprehensively, effectively benefiting graduates employment.

\section{POLICY ANALYSIS}

The pioneer policies during the COVID-19 period are the core policies directing the path and development trend of the government's college graduate employment work. The pioneer policies in Zhejiang Province were carried out quickly and systematically, and the overall effect was good. However, in cities such as Shaoxing, Jinhua, Jiaxing, Zhoushan, and Taizhou, the pioneer policies were not as many as in other cities. Therefore, taking Jinhua city as an example to carry out the survey and research can be helpful to understand the details of college graduate employment and entrepreneurship work of small and micro-enterprises.

\subsection{Existing Normal Policy Being Solid Foundation of College Graduate Employment Work}

According to the survey, it was found that in the early stage of the COVID-19 period, Jinhua City had fewer pioneer policies than other cities because it had a rich foundation of employment and entrepreneurship policies for college graduates, and the normal employment and entrepreneurship work was stable and solid.

Through the research on the employment and entrepreneurship policies of Jinhua City in the past three years, it is found that Jinhua Municipal People's Government issued implementation policies on employment and entrepreneurship as early as in 2018 [5], stipulating that it is required to provide assistance for college graduates, rural laborers and entrepreneurship incubation bases, school-enterprise cooperation in field bases, etc. 
The normal work system of employment and entrepreneurship is comprehensive and systematic. For example, it not only implements the employment and entrepreneurship promotion plans for college graduates and also the grassroots growth plan, guides graduates to work in small and medium-sized enterprises, grassroots public management and social service positions, and grassroots institutions and institutions, and implements supporting policies for graduates to participate in grassroots service projects and to be enrolled in the army. Meanwhile, training is also carried out to improve the ability of outstanding entrepreneurs. The maximum government employment subsidy standard is 10,000 yuan per person per year. At the same time, rewards and subsidies for school-enterprise cooperation in field bases are issued, increasing the enthusiasm of enterprises to introduce and cultivate skilled talents. High-quality employment community rewards and subsidies are also provided.

\subsection{Implementation of Normal Employment Policy Benefiting College Graduates}

The policy of employment and entrepreneurship in Jinhua City is not only systematic and comprehensive, but also helps refine the target positioning, which is of great operational significance.[6] For example, in terms of employment and entrepreneurship policies for college graduates, within 2 years of graduation, they can get employment in small, medium and micro-enterprises with an annual employment subsidy of 3,000 yuan; within 5 years of graduation, they can receive subsidies of 10,000 yuan per year if they work for the disabled and housekeeping services. At the same time, it is stipulated that the duration of the above two subsidies shall not exceed 3 years. Social organizations that hire college graduates can equally enjoy the supporting policies for enterprises to attract laborers. College students and graduates within 5 years of graduation will be given a onetime entrepreneurship subsidy of 10,000 yuan for their first entrepreneurship.

\subsection{Adjusted Normal Policies in Abnormal College Graduate Employment Situation to Improve Working Efficiency during COVID-19 Period}

Although Jinhua City has a rich foundation of employment and entrepreneurship policies for college graduates, the policies were still updated during the COVID-19 period, and related work has been improved and upgraded.[7] In 2020, Jinhua City issued relevant policies to guide the distribution of employment subsidies for small, medium and micro-enterprises to enrol college graduates, stipulating that if they sign labor contracts for more than one year with a company and the social insurance premiums for more than 12 months in accordance with the law, the government will give the company a one-time payment of 1,000 yuan per person as employment subsidies. This has added subsidies to the original basis. To give subsidies to both employees and employers develops the normal college graduate entrepreneurship and employment work under abnormal conditions. It is worthy of attention and recognition. [8]

In May 2020, Jinhua launched the first intelligent public employment service platform in Zhejiang Province-the employment smart distribution system, which enables enterprises and individuals to achieve intelligent matching of service items. At the same time, twelve policies for ensuring employment and stabilizing talents were introduced to provide "upgraded" policy support for corporate talents. For example, to increase job stabilization subsidies, to double stabilization subsidy return standard from $50 \%$ to $100 \%$ of the unemployment insurance premium paid by the enterprise and its employees in the previous years.

Policies were also issued to attract college graduates to come to Jinhua for employment and entrepreneurship. For example, in the next two years, the city's state-owned enterprises will provide no less than $50 \%$ of new jobs to recruit college graduates; the city's small, medium and micro-enterprises recruiting college graduates of the graduation year will receive a subsidy of 1,000 yuan per person; college students and graduates within 5 years of graduation can receive a subsidy of 100,000 yuan for entrepreneurship when they first establish companies providing services for the old, the disabled, or for housekeeping and modern agriculture. And there are also grant subsidies for college students to stay abroad. For college students who do not meet the requirements for receiving unemployment benefits after becoming unemployed, they can participate in social security in the form of flexible employment, and monthly retention of 1152 yuan will be given; those who are unemployed during the year and the family with no housing can enjoy a rent subsidy of up to 6 months.

\section{RESULTS AND DISCUSSION}

Compared with migrant laborers and high-level talents inside and outside the province, there is a lack of employment policies for new college graduates. With March 2020 as the time node for policy review, focusing on the first employment policy for college graduates in small and micro-enterprises during the COVID-19 period, a total of 98 employment policies publicly released by governments at all levels in Zhejiang Province through the online platform could be found: 5 are related policies issued for new employment; 6 related policies issued for enterprise employment; 53 related to enterprise employment: 9 focusing on talent introduction; 77 related to talent introduction. These policies benefit different groups. 55 relevant policies are for key enterprises; 77 relevant policies are for small, medium and microenterprises. 22 relevant policies are for migrant workers; 7 relevant policies are for new graduates, including 2 for graduates from higher vocational colleges; and there are 
also 14 for high-level talents inside and outside the province. But there are no employment policies for small and micro-enterprises employing new college graduates. But there are still some problems.

First, the existing guiding principles and policies have been implemented regionally, and the employment policy practice of the grassroots government is uneven. Therefore, it is difficult for grassroots governments to implement employment policies following the guiding principles issued by higher-level governments.

The second is the right balance between the operational rules of employment policies and the dynamic development of human resources employment demand in relevant regions. Existing policy support mainly targets talents with skills in short supply, and seldom pays attention to the conventional large-scale demand for basic talents, and the main problem of employment is the retention of basic talents. According to the "Research Report on the Group of College Students with Employment Difficulties" released by Zhilian Zhaopin Recruiting in June 2020, by the end of June this year, 26.3\% of 2020 new graduates enrolled on the platform were still seeking jobs.[9] There are differences in the employment difficulty degree among different educational background groups. Among the group of new graduates with employment difficulties in June, the proportion of undergraduates was the highest at $65.6 \%$, followed by vocational students at $26.2 \%$, and the proportions of masters and doctors were $8.0 \%$ and $0.14 \%$, respectively. This shows that there is a problem of tight balance in the dynamic development of large areas of human resources employment demand in relevant regions.

To solve these problems, the following suggestions are provided.

\subsection{Releasing New Policies and Improving Existing Policies' Working Efficiency}

The first is to develop new policies to solve the problem of structural deficiencies in policies for new employment in small and micro-enterprises for college students. At the level of provincial and municipal government agencies, the policy for migrant laborers and high-level talents inside and outside the province should be learnt from. At the grassroots government level, employment work highlight models should be set, and the role model should lead the rest of the working units. The effective policy practice should be used to promote the implementation of policies in the whole province. Through the research, it is found that some urban government units such as Jinhua City have a rich foundation of employment and entrepreneurship policies for college graduates, and their normal employment and entrepreneurship work is stable and solid. These cities are good examples and play the role of an "important window", their work experiences are worth spreading.

The second is to carry out employment governance informatization to improve work effectiveness.
Information-based collaborative management should be used to coordinate employment-related functional departments so that all the existing policies that benefit enterprises and laborers will be publicly announced to facilitate policy-beneficial groups to self-study. At the same time, the policy implementation cycle should be shortened and the efficiency of policy application should be improved.

\subsection{Classifying the Beneficiaries and Improving the Operability of Policy Implementation}

The existing guiding principles and policies are implemented regionally, and some grassroots governments have not formulated detailed implementation rules. Some of the implemented policies are closely balanced with the dynamic development of relevant regional human resource employment needs. The existing policies mainly benefit talents with skills in short supply instead of paying attention to the conventional large-scale demand for basic talents. The main problem of employment is the retention of talents caused by the structural contradictions in the employment of basic talents. Therefore, the policy beneficiaries should be classified so that the benefits can be targeted, and the implementation of grassroots employment policies can be directly checked and benchmarked.

The second is to develop performance rules to improve the operability of policy effectiveness. At present, the classification of employment policies all target the starting employment conditions of college graduates. These are the basic policies, but the main beneficiaries of these policies should benefit common college graduates who have low employment competitiveness and change jobs frequently. The employment policies should be upgraded solving practical problems to meet the actual needs of the people's livelihood based on regional employment conditions. Scientific assistance policies should be developed such as rental subsidies that are conducive to the continuation of the initial employment time for college students to avoid too high frequency of reemployment. At the same time, other performance policies can be formulated to make the employment policy more systematic and complete, and support college graduates' sustainable career development.

\section{CONCLUSION}

According to the survey and the above analysis, employment policy works to benefit college graduates in Zhejiang Province. There are solid foundation of college graduate employment work including comprehensive normal employment policy and regionally practical policy implementation. Meanwhile, normal policies were adjusted to meet the needs of the abnormal college graduate employment situation during the COVID-19 period. 


\section{ACKNOWLEDGMENT}

Investigation and Countermeasures on Employment Situations and Trends of College Graduations in Small and Micro-enterprises in Zhejiang Province in late COVID-19 epidemic (2020YQJY358), Education in COVID-19 Epidemic: Planning Subject of Zhejiang Provencal Education Sciences in 2020

\section{REFERENCES}

[1] Survey: Over half of college students work in small, medium and micro-enterprises after graduation [OL] https://www.sohu.com/a/302089864_123753

[2] Small and medium-sized enterprises contribute $50 \%$ of tax revenue, $60 \%$ of GDP, and $70 \%$ of technological innovation, but they are struggling to survive! Now I am finally saved! [OL]

https://www.sohu.com/a/250562431_465088

[3] Brief Introduction to Zhejiang Economic Operation from January to February [OL]

http://tjj.zj.gov.cn/art/2020/3/30/art_1562012_42421635 .html

[4] The "Research Report on the Group of College Students with Employment Difficulties" is released [OL]https://baijiahao.baidu.com/s?id=16749668617693 $23226 \& w f r=$ spider $\&$ for $=p c$
[5] Implementation Opinions of Jinhua Municipal People's Government on Doing a Good Job in Promoting Employment at Present and in the Future [OL]http://www.jinhua.gov.cn/art/2019/5/6/art_122916 0909_52971167.html

[6] Interpretation of Jinhua Municipal People's Government's Implementation Opinions and Policies on Doing a Good Job in Employment and Entrepreneurship at Present and in the Future

[OL]http://www.jinhua.gov.cn/art/2018/6/12/art_12291 60387_1039791.html

[7] Notice of Jinhua Municipal Human Resources and Social Security Bureau Jinhua Municipal Finance Bureau on Carrying out Enterprise Training Subsidy Work[OL]http://rsj.jinhua.gov.cn/art/2020/11/9/art_122 9164922_1706753.html

[8] Twelve Articles for Ensuring Employment and Stable Talents in Jinhua City [OL] https://www.jhnews.com.cn/xw/sh/202005/t20200531_ 295345.shtml

[9] Zhaopin Recruitment released the "Research Report on the Group of College Students with Employment Difficulties". In June, $26.3 \%$ of the 2020 graduates are still seeking jobs on the platform[OL] https://baijiahao.baidu.com/s?id=167522169432385729 $7 \& w f r=$ spider $\&$ for $=p c$ 